NBER WORKING PAPER SERIES

\title{
THE AFFORDABILITY GOAL AND PRICES IN THE NATIONAL FLOOD INSURANCE PROGRAM
}

\author{
Matthew E. Kahn \\ V. Kerry Smith \\ Working Paper 24120 \\ http://www.nber.org/papers/w24120 \\ NATIONAL BUREAU OF ECONOMIC RESEARCH \\ 1050 Massachusetts Avenue \\ Cambridge, MA 02138 \\ December 2017
}

Smith's research was partially supported by the Property and Environment Research Center (PERC) under the Julian Simon Fellowship program in 2017. Support for the undergraduate RA was thru CENREP. Thanks are due Dan Benjamin, Barry Goodwin, and Wally Thurman as well as to research fellows and staff at PERC for comments on an earlier draft of this research and their assistance throughout the second author's stay; to Nicolai Kuminoff and Alvin Murphy for assistance in helping the second author to access some of the data used in the analysis; and to W. Michael Hanemann for helping the second author to access to the National Research Council commissioned "proof of concept" study (North Carolina Floodplain Mapping Program [2015]). Outstanding research assistance was provided by Ben Whitmore, CENREP undergraduate research fellow, at Arizona State University. The views expressed herein are those of the authors and do not necessarily reflect the views of the National Bureau of Economic Research.

NBER working papers are circulated for discussion and comment purposes. They have not been peer-reviewed or been subject to the review by the NBER Board of Directors that accompanies official NBER publications.

(C) 2017 by Matthew E. Kahn and V. Kerry Smith. All rights reserved. Short sections of text, not to exceed two paragraphs, may be quoted without explicit permission provided that full credit, including $(\odot)$ notice, is given to the source. 
The Affordability Goal and Prices in the National Flood Insurance Program

Matthew E. Kahn and V. Kerry Smith

NBER Working Paper No. 24120

December 2017

JEL No. D3,H23,Q5

\begin{abstract}
$\underline{\text { ABSTRACT }}$
The United States Gulf Region features areas that face significant flood risk. Climate change may further elevate this risk. Home owners in such areas face potentially large asset losses and property maintenance costs. Anticipating these challenges, the Federal government has enacted a complex set of policies through its National Flood Insurance Program (NFIP). The NFIP offers reduced insurance rates for homes built before rate maps were drawn and grandfathers rates for homes when new maps increase their risk ratings. This paper asks if the goal of affordable NFIP insurance rates for the high risk Gulf Coast areas is warranted? We compare the income distribution of the set of people who live in the areas that face the highest risk of flooding relative to nearby areas. Our findings imply reduced rates for high risk areas cannot be justified based on the assumption that low income households live in these areas.
\end{abstract}

Matthew E. Kahn

Department of Economics

University of Southern California

KAP

Los Angeles, CA 90089

and NBER

kahnme@usc.edu

V. Kerry Smith

Department of Economics

W.P. Carey School of Business

P.O. Box 879801

Arizona State University

Tempe, AZ 85287-9801

and NBER

kerry.smith@asu.edu 
The Affordability Goal and Prices in the National Flood Insurance Program

\author{
Matthew E. Kahn and V. Kerry Smith
}

\title{
1. Introduction
}

The National Flood Insurance Program (NFIP) was established 50 years ago. Currently it is about $\$ 25$ billion in debt to the US Treasury. With current debt limitations, the program would not have been able to respond to the payouts required for hurricanes Harvey and Irma without $\$ 16$ billion in debt forgiveness provided by the disaster relief bill that Congress passed late in October, $2017^{1}$. Insurance premiums do not cover required payouts, especially for severe storms. One of the NFIP goals calls for a program that ensures affordable insurance prices. Current policies to meet this goal have created a complex system of subsidies and grandfathered insurance rates that are below actuarial levels, and contribute to the persistent revenue shortfalls. Indeed, $85 \%$ of the policies in the highest risk areas are subsidized ${ }^{2}$. Efforts to change the program in 2012 were reversed in $2014^{3}$. Recent House and Senate reauthorization bills for the program continue to focus on affordability rather than insurance rates reflecting risks.

\footnotetext{
${ }^{1}$ This summary is based on a news account reported by Gloria Gonzalez in Business Insurance, October 27, 2017.

2 The Congressional Budget Office's recent analysis (CBO [2017]) matched NFIP policies in effect as of August 2016 to the flood zone designations. 85\% of the policies in the highest risk zone (V) paid insurance that did not reflect their flood risks. P.16

${ }^{3}$ In 2012 Congress recognized the need for reform in the rates for the NFIP and passed the Beggert Waters Flood Insurance Reform and Modernization Act. The core principle of this legislation was to move the NFIP toward a riskbased set of premiums “... that better reflected expected losses from floods at insured properties”( National Research Council [2015] p.51). As a result of community concerns with the implications of the price increases, in
} 
Our analysis answers a direct question: is the focus on the affordability of the NFIP insurance rates for the high risk Gulf Coast areas warranted? We argue that an answer to this question should be based on those living in the areas that face the highest risk of flooding. This approach is consistent with evaluating the program based on the characteristics of the households who could access it. To answer this question, we compare incomes of Gulf Coast households in shoreline areas with those in the adjoining interior locations. Our analysis uses two different sources for income information, IRS summary tables at the zip code level and the individual mortgage applications available through the Home Mortgage Disclosure Act of 1975 (HMDA) and two spatial scales - counties and zip code areas. With the HMDA data, we consider the record for 25 consecutive years from 1989 to 2014 and with the IRS records for seven years, 2007 and 2009 to 2014.

Both sources of income data and spatial scales confirm that households in the shoreline areas of the Florida Gulf Coast have higher real median incomes than those in interior locations. For three of the other four Gulf States there is evidence supporting this conclusion, but it is not as consistent for both data sources and spatial scales. For Louisiana, the ranking of real median incomes is reversed. Households in the interior locations have higher median incomes than those in the shoreline areas.

Because spatially delineated insurance rates can provide important risk signals in the face of the increasing likelihood of severe storms with climate change, our results suggest that the affordability objective of the NFIP can be realized by targeting low income households, rather than by setting insurance rates applicable to all who locate in high risk areas. Other studies have

2014, Congress passed the Homeowner Flood Insurance Affordability Act which changed the process associated with removing pre-FIRM subsidized rates and reinstated grandfathering. 
considered the impact of floods by income group (Sarmiento and Miller [2006], Congressional Budget Office [2017]) or used measures of the "regressivity” of the premiums, payouts, and incomes (Bin, Bishop and Kousky [2017]). These studies focus on existing policy holders. By contrast, our objective is to consider the households who would be at risk even though they may live in communities that have not enrolled or before they decided to purchase insurance. In practice we cannot observe households in this proposed ex ante context. As a result we use different sources of incomes of households who would be homeowners in these high risk areas. Our detailed micro-level records on household income for those buying or owning homes allow us to use a finely delineated spatial scale and a longer time span for our analysis. Our findings offer an explanation for some of these earlier studies’ conflicting conclusions.

\section{Context}

The original goals of the NFIP were to encourage states and local governments to restrict development in locations with high risks of flooding and thereby promote flood plain management and to provide affordable insurance, assuring high take-up rates, so the impacts of floods would be mitigated thru a public-private partnership. The insurance was supposed to be provided thru private firms with the Government assuming “... that proportion of the risk represented by the difference between these policyholder-paid premiums collected and the estimated (actuarial) premium amounts for all policies written and in force under the program.”4 In about a decade the federal government took responsibility for the rate setting and the risk and the newly formed Federal Emergency Management Agency (FEMA) was given responsibility for the program.

\footnotetext{
${ }^{4}$ This quote is taken from the National Research Council [2015] report on the program and cites a 1967 Senate report of the Committee on Banking and Currency, p 2-26 of the review draft of the NRC report.
} 
A key issue in understanding the NFIP is the program's desire to assure that insurance rates are affordable for those in high risk areas. This goal necessarily implies that to sustain the program other sources of funding for these subsidies must be identified. In the case of the NFIP it comes from two other sources: higher prices for insurance in areas with lower risk and loans from the U.S. Treasury. The first source of funds, thru cross subsidies among policy holders, only "works" when a sufficient number of low risk individuals purchase insurance. Hence it should not be surprising that multiple analyses of the program have found predicted revenue shortfalls with the current system. The second strategy implies the US taxpayers also subsidize the program.

Currently the NFIP program has a number of provisions that lead to insurance rates below actuarially fair levels. This insurance is available in participating communities. For individual homeowners policies it allows up to $\$ 250,000$ of coverage for structures and $\$ 100,000$ for contents. The insurance rates primarily affected by these subsidizes involve the first $\$ 60,000$ of coverage for the structure. Homes built before there was a flood insurance rate map (FIRM) for their community (labeled as pre-FIRM) and in flood Zones A or V are not subject to the rates based on the flood risks they face, as determined by the map ${ }^{5}$. CBO [2017] estimates the average subsidy of these preferential rates at $40 \%$. Under a risk based system for pricing, changes in the flood maps that imply increased risks, as for example due to climate change, would imply higher rates. Instead, current policy maintains them at the prices corresponding to the earlier FIRM. Efforts to alter this policy in 2012 were reversed in response to community opposition in $2014^{6}$.

\footnotetext{
${ }^{5}$ Zone $\mathrm{V}$ designates a coastal area where the velocity of wave action adds at least 3 feet to the water level that is reached in a 100year flood. Zone A designates a 100year floodplain or on in which there is at least a 1 percent annual probability of flooding and not designated as Zone V. Zone X is any mapped area not inside a 100 year floodplain. See Appendix B of the Congressional Budget Office [2017] report for discussion of the NFIP subsidies. ${ }^{6}$ In 2012 Congress recognized the need for reform in the rates for the NFIP and passed the Beggert Waters Flood Insurance Reform and Modernization Act. The core principle of this legislation was to move the NFIP toward a risk-
} 
These homeowner concerns likely reflect the capitalization of their access to these subsidies into the values of the homes in pre-FIRM areas meeting the program's eligibility criteria. The magnitude of these "grandfathered" subsidies differs by flood zone, elevation conditions for the property, and whether they received federal disaster assistance. According to CBO they also average about $40 \%$.

The disparity between risk based insurance rates and current NFIP practice is important because over the past decade there has been growing acceptance that global warming will increase the destructiveness of hurricanes. This research has found that tropical cyclones, labeled hurricanes when they occur in the North Atlantic Basin, are likely to grow in strength with global warming $^{7}$. As a result, current policy misses an important opportunity to use insurance price signals to promote adaptation. Actuarial rates would be consistent with one of the original objectives of the program to guide future development away from locations that face flood hazards.

\section{Affordability Concern, Income Distributions, and Flood Insurance Rates}

Our analysis considers the importance of affordability by asking about the incomes of those households who would have access to the insurance in high risk areas. To address this question

based set of premiums “... that better reflected expected losses from floods at insured properties”( National Research Council [2015] p.51). As a result of community concerns with the implications of the price increases, in 2014, Congress passed the Homeowner Flood Insurance Affordability Act which changed the process associated with removing pre-FIRM subsidized rates and reinstated grandfathering.

\footnotetext{
${ }^{7}$ Knutson and Tuleya [2004] conducted 1296 simulations using data from nine different general circulation climate models. All of the models were subjected to the same set of assumptions in these simulations. The experimental treatments assume increasing CO2 accumulation under an 80 year time horizon. The high CO2 scenario was defined as a departure from a control situation where weather conditions were determined based on the existing mean seasonal climatology also for the same 80 year time horizon. The treatment for the high CO2 was described as a linear trend with a 1\% growth in CO2 each year. They found that there was an increased frequency of storms in the higher wind categories and these are the more damaging storms.
} 
we compare the income distributions for households in the coastal areas of the Gulf States to those living in interior sections of the same states. Tiebout [1956] sorting models would imply that if coastal locations are attractive to households, due to the amenities they provide, then we would expect higher income households would disproportionately select these locations. More formally, when preferences are assumed to satisfy the single crossing property, the locational equilibrium that describes how households sort among communities, considering both housing prices and local public goods and amenities conveyed by selecting a community, implies stratification by income. The sorting model implies communities can be ordered by the housing price and the level of amenities regardless of whether there is a single amenity or an index for a vector of amenities ${ }^{8}$. Assuming zero moving costs, the sorting equilibrium will produce a set of prices such that the community with the lowest price of housing is matched to the lowest level of the index of public goods and local amenities. This logic is the basis for our proposed analysis of affordability.

Of course, when the set of amenities simultaneously conveys a risk such that higher levels of the index of public goods experience a higher risk of damage from storms, then the predictions are less clear-cut. It will depend upon the trade-off between coastal amenities and the households' knowledge of those risks and extent of their aversion to risk. It is certainly possible that these risks would undermine the predictions of income stratification. The process of disentangling these effects would require a model that reflects at least three, interdependent decisions. The first of these is associated with the household's choice to locate in a high risk

\footnotetext{
${ }^{8}$ See Nechyba [1997] and Epple and Sieg [1999]. In these models that assume each individual has the same index for quality, communities can be ranked in the same way by each potential resident, considering the vector of amenities that contribute to this quality index and the housing price. Consumers can have different levels of preference for the index of amenities but it is usually assumed their preferences are the same in other respects such as the role for income and relative prices of housing. In this case, the communities can ranked on a single index of quality. In the absence of preference heterogeneity about the importance of quality the model predicts income stratification.
} 
area. That decision would be conditioned upon whether the community selected is participating in the NFIP. If it is not, then under a framework that assumes intertemporal optimization and full information for household behavior, the choice would take into account the household's perception of the process for how a community’s decision about participating in the NFIP might be altered. Finally, given a location choice and access to the NFIP, the household would decide whether to purchase insurance and the amount of coverage. This inter-temporal formulation of the decision process implies these three decisions are consistently integrated. That is, a household evaluates each location based on the fact that these sub-decisions have already been optimized. In all cases the decision process is impacted by the NFIP insurance rates. Moreover, regardless of whether one accepts that households on average act as if they solve this dynamic problem or they make decisions using another behavioral rule, our approach focuses on the outcomes of these decisions and whether they are consistent the implicit assumption that those living in high risk areas need to have subsidized insurance rates. We use the observed income distributions for coastal locations in comparison to interior locations to consider the effects of the sorting hypothesis.

Two spatial scales were selected. The first of these corresponds to counties in each state with coastal shorelines. The income distribution measures for these counties are compared to interior counties in the same state ${ }^{9}$. The second considers the shoreline zip codes compared to the adjacent interior zip codes. As our sketch of the logic for an intertemporal sorting process implies, a composite of market conditions, amenities, storm risks, along with policy induced incentives influences who buys homes in shoreline locations as compared to interior areas, but we do not attempt to separate these effects.

\footnotetext{
${ }^{9}$ This logic is broadly consistent with that used in the CBO [2017] analysis of the affordability of insurance rates in relationship to household income.
} 
The first set of data on incomes is for applicants for home mortgages. These data are available through the requirements of the Home Mortgage Disclosure Act (HMDA) of 1975. Since a mortgage application is an economic decision, there may be concerns about the selection process that conditions the income information available thru HMDA for our analysis. As a result, we also use a second set of administrative data constructed at the zip code level by the Internal Revenue Service from income tax returns. We use the conditional income distributions for those households who took a mortgage interest deduction as a proxy for homeownership.

We assembled over 500 million records for all the HMDA mortgage applications in the United States over the period 1989 to 2014. From this “universe” we selected applications for the states bordering the Gulf of Mexico: Alabama, Florida, Louisiana, Mississippi, and Texas. In the case of Florida we exclude the counties along the Atlantic coast ${ }^{10}$. The IRS income distribution information was available between 2007 and 2014. Both sets of income information were used to construct an estimate for the real (in \$2015) median income. The HMDA data also allowed two other measures of the distribution -- the real income defining the $90^{\text {th }}$ percentile and the income defining the $10^{\text {th }}$ percentile of the distributions.

With the HMDA records these summary measures were developed for shoreline and interior counties and for shoreline and adjacent zip codes for each state with locations on the Gulf. The IRS records were used only at the zip code level. In this case we also evaluated the relative frequencies for each of the income classes identified by the zip codes distinguishing shoreline and adjacent interior locations. The same definitions for the income intervals defining

\footnotetext{
${ }^{10}$ Analyses of the Atlantic Coast at the county and zip code level using the HMDA records provide results comparable to that of Florida's Gulf coast. That is, they support income stratification.
} 
the distributions were used in six of the years with the IRS reports ${ }^{11}$. The intervals are reported in nominal terms ${ }^{12}$.

It might be argued that interior locations also face risks of damage from hurricanes. The 2017 CBO study of the NFIP defined coastal counties as those where expected claims from storm surges or precipitation from coastal storms accounted for seventy five percent of the expected claims. This definition does not match ours, which is based on the presence of shoreline for each of our coastal counties. Nonetheless, based on the graphical presentation in Figure 2 of the CBO report all but one of the counties identified with expected shortfalls exceeding \$10 million had shoreline and most of them were Gulf coast counties.

Equation (1) outlines our basic empirical model. We test for differences in each measure of the income distribution separately using the interaction variables defined to identify shoreline and interior areas that are associated with either counties or zip codes, depending on the level of spatial aggregation used to measure the distribution. Our test evaluates the joint null hypothesis that the coefficients for these interaction terms are all simultaneously zero for all time periods (i.e. $\gamma_{t}=0$ for all $\mathrm{t}$ ) represented in our sample.

$$
y_{i t}=\sum_{t} \beta_{t} l(t)_{i t}+\sum_{t} \gamma_{t} l(t)_{i t} \cdot C(i)_{i t}+\varepsilon_{i t}
$$

where: $y_{i t}$ is the measure of the income distribution in year $t$ for county i;

\footnotetext{
11 The distribution remained fixed from 2009 to 2014. In 2007 the limits were altered. The 2009 to 2014 are given in Tables 2 and 3. The 2007 limits were: Under \$10,000; \$10,000 under \$25,000; \$25,000 under \$50,000; 50,000 under \$75,000; 75,000 under \$100,000; \$100,000 under \$200,000; and \$200,000 or more.

${ }^{12}$ We used the Stata command gdsum, developed by Daniel Klein, University of Bamberg, daniel1.klein@gmx.de to estimate the median and did not set an upper maximum for the open ended top interval in these distributions.
} 
$l(t)_{i t}$ is an indicator variable $=1$ when the estimated measure of the income distribution for year $t$ and county( or zip code) $i$ corresponds to year $t$ and 0 otherwise (i.e. a dummy variable for the year of the application).

$C(i)_{i t}$ is an indicator variable $=1$ when the estimated measure for the income distribution for county (or zip code) i corresponds to a county (or zip code) with shoreline on the Gulf coast and 0 otherwise (i.e. a dummy variable identifying the areas with shoreline).

$\varepsilon_{i t}$ is a random error

The most direct way to display our findings is with a plot of the estimated parameters the $\hat{\beta}$ 's for each year and spatial definition associated with interior locations and the $\hat{\beta}+\hat{\gamma}$ for the shoreline locations. Figures 1a, b, and c display the results for the real median income for Gulf Coast locations in Florida. Figures 1a and b are based on the HMDA records at the county and zip code spatial scales respectively. Median income in \$2015 is higher for all coastal locations for the county definition for all years and for all but one year (1995) with the zip code spatial scale. Tests of the joint null hypothesis that these differences are zero are rejected for both definitions of the spatial scale used to measure the income distributions with HMDA records. The F statistics and associated p-values for the joint tests are reported in the first column of Table 1. Figure 1c is a plot of the median income estimated from the IRS tabulations for 2007 and 2009 through 2014. The IRS tabulations in 2008 do not report distributions for those taking the mortgage interest deduction and cannot be included. Once again, the test results (also reported in the first column of Table 1) support the conclusion that median incomes are higher for those homeowners in shoreline locations compared to interior locations. 
Our models estimated using the IRS data for the relative frequencies in each income class over time cannot take account of changes in the price level. As a result, tests of the differences in these measures of the income distribution over time confound price level changes with indications of shifting in the income distribution. Nonetheless, for Florida, all the income classes except the lowest category reject the null hypothesis of equal relative frequencies over time and support the greater concentration of households in the higher income brackets. Finally, the other measures of the income distribution computed with the HMDA records are also generally consistent with the conclusion that households' locational choices lead to stratification in the income distribution, with higher income levels associated with shoreline locations.

These results for Florida help to explain the differences in the findings for the three earlier studies that can consider the characteristics of the households affected by the NFIP. Before discussing this comparison, it is important to repeat that our focus is an ex ante perspective. We are attempting to characterize the households who would face the risks and insurance rates the NFIP is intending to serve. The three, earlier studies of households affected by the flood insurance program estimate the household income of policyholders. In all cases data restrictions (usually confidentiality requirements) prevent matching the policy information to the incomes. Ben, Bishop, and Kousky [2017] begin their analysis with FEMA information on policies in force between 2001 and 2013. They also consider the individual records on premiums and insurance claims in that same period and aggregate these data to the zip code level. These measures are compared to median household income from the Census ${ }^{13}$. Since these measures are available in two years that overlap their records on NFIP policyholders (i.e. 2000 and 2010), the authors use linear interpolation to fill in the incomes for intermediate years for each zip code.

\footnotetext{
${ }^{13}$ It was not clear from the description given in the paper whether the household median income was for those in single family homes or combined with families likely to be renting.
} 
Their analysis considers Lorenz and concentration curves for all years and zip codes using real income as well as the NFIP premium and payout measures to evaluate progressivity ${ }^{14}$.

The CBO study has a similar starting point, namely the records on policies in force. In this case it is for a single year 2016. Median household income for families living in single family homes at the census tract level, weighted by the share of NFIP policyholders in the tract, is the income measure used in their analysis. Coastal areas were found to have lower income (\$74,600 in 2016 dollars) in comparison to non-coastal $(\$ 81,200)$ considering all tracts in the 48 states and the District of Columbia that had NFIP policies in force. The Bin et.al. analysis focused on different measures. Their analysis finds that premium shares are larger than income shares for lower income zip codes. However, they are cautious in interpreting these findings and conclude calling for the need to consider the relationship between income and the receipt of a pre-FIRM price discount.

The last study by Sarmiento and Miller [2006] uses a hydrologic model (HAZUS) to simulate flood impacts at the census block level. It relies on the NFIP loss database from known flood events to infer losses by flood size in the simulation analysis. Comparing these estimates for a 100 year flood event using simulated losses for 20 communities across the US within special flood hazard areas they found a higher fraction of households within the higher income brackets own residences in high risk areas, conjecturing that these are near coastlines and lakes with high amenity values. Their analysis also suggested that low income households appear to be located in higher risk floodplains as compared to the middle income groups.

\footnotetext{
14 Their robustness analyses eliminate years with major hurricanes to evaluate the effects on their conclusions.
} 
These three analyses contrast with our approach. We examine the results at a finer spatial scale comparing shoreline and adjacent units with either a county or a zip code definition for the “community” in each state separately. We treat each year separately and examine the consistency in the findings across years. We believe that it is likely that past studies’ composite analysis of coastal and non-coastal areas made it difficult to distinguish risk and amenity effects. Our analysis for the case of Florida, where the amenity effects are perhaps most distinctive, illustrates the importance of the finer spatial resolution. Both risk and amenities are present for the shoreline areas. Thus, distinguishing locations where each set of influences may be as important as the other provides an opportunity for the sorting logic to be revealed depending on how the equilibrium outcomes reflect the way preference heterogeneity balances risk and amenities. If the samples combine shoreline and non-shoreline locations where the amenities may not be present in some of the shoreline locations for some of the observations and are present in other observations along with the flood risks, then it will be difficult to reconcile the outcomes of the sorting behavior.

Table 2 reports the same tests for the four other Gulf Coast states using the same two spatial scales as well as the HMDA and IRS data. In these cases, the results depend on the spatial scale used for measuring the income distribution. Moreover, for Louisiana the relationship between shoreline and interior income distributions is reversed. Consider first the states that imply shoreline income distributions exceed those associated with interior locations, namely Alabama, Mississippi, and Texas. For Alabama and Mississippi the conclusions are generally supported using HMDA data and the shoreline counties as the spatial unit to estimate the income distributions. For Texas, the income measures at the zip code level support income stratification. Thus, none of these three states matches the consistent record of rejections for the hypothesis that 
shoreline locations are not distinguished by household income levels as we found in the case of Florida. Estimates in these three states based on the IRS data never allow a rejection of the null hypothesis.

There are a number of possible reasons for these mixed findings. First, it is certainly possible that heterogeneity in the coastal amenities could provide one explanation. As we noted, an advantage of our analysis was that the findings did not require a set of maintained assumptions about how coastal amenities (and dis-amenities) would be measured. To resolve these questions further research on the diversity of amenities by spatial scale would be needed. This task is beyond our scope here and we argue not essential to the policy implications of our results.

A second possibility concerns the diversity in conditions in the comparison group associated with defining interior locations. At the county level, the relative number of interior counties compared to coastal locations in these states is larger than for Florida. For example, in the case of Texas there are 13 times the number of interior counties to shoreline counties. To investigate the implications of this large disparity in Texas, we repeated the analysis of income distributions considering only the adjacent Texas counties. This replication did not alter our conclusions at this spatial scale in the Texas comparison.

Developing an overall assessment for the differences between the decisive results for Florida and the mixed findings in these three states requires that we explain more specifically what we hope to establish from these comparisons. Our objective is to offer evidence that the implicit premise in nearly all discussions of the NFIP pricing policies does not justify subsidies. That is, all these discussions implicitly assume that households living in high risk areas, 
especially those in shoreline locations prone to hurricanes, cannot afford insurance. We believe our findings offer sufficient evidence to undermine this conclusion, as a guide to setting prices that would apply to all households. Instead, there is support for the conclusion that in these four states some form of income stratification associated with shoreline versus interior location is taking place. Thus, policies that distort insurance prices so they do not clearly reflect the risks of shoreline locations cannot be justified on equity grounds.

The reversal in ranking for the income distributions in coastal versus interior locations in Louisiana does not undermine our overall conclusion. Louisiana's coastal locations are a majority wetlands compared to the other coastal locations of the United States ${ }^{15}$. Moreover, a recent report by the US Geological Survey (Covillion et al. [2011]) indicated that 1.2 million acres of land has been lost in Louisiana between 1992 and 2010 and the majority of the land loss in this report is composed of tidal wetlands. Recently Louisiana’s Coastal Protection and Restoration Authority [2017] released a Master Plan predicting continued and more significant land loss than previously expected ${ }^{16}$. As part of the Plans' effort to inform the public, it includes an interactive online mapping capability (http://cims.coastal.louisiana.gov/masterplan/) that displays, among other elements, the land change, flood risks, and composition of coastal vegetation in locations throughout the state. According to this resource, all of the coastal areas of the state are composed of marsh or wetlands and thus we would not expect them to support the types of residential locations associated with HMDA records.

\footnotetext{
${ }^{15}$ Using Arcgis we computed the percentage of each shoreline county that was composed of wetlands. This averaged 57 percent.

${ }^{16}$ See Data Center [2017] and Coastal Protection and Restoration Authority of Louisiana [2017] for further details.
} 


\section{Implications}

Our analysis of the income distributions for homeowners who select shoreline locations clearly supports income stratification in coastal areas of Florida. For three of the remaining Gulf Coast states, our conclusions about income stratification depend on the spatial scale used to estimate the distribution. Nonetheless, we argue they provide sufficient evidence for concluding higher income households are more likely to select coastal locations and this tendency has persisted over more than two decades based on the HMDA applications. These results are important because the effects of the equilibrium adjustments of households that lead to income stratification appear to have been overlooked in most policy analyses intended to identify proposals for reforming the program. For example, the CBO analysis of policy options for the NFIP classifies policies in ways that appear to understate the importance of assuring that the prices for insurance reflect the risks of each location. The report categorizes its policy proposals according to four criteria: (a) efforts to increase policy receipts; (b) efforts to reduce subsidies; (c) efforts to shift costs away from the insurance program; and (d) efforts to adjust rates to better reflect risk. The report rates its proposed reforms based on: improving solvency, aligning premiums and risk, and maintaining low costs for all policy holders. Of the twelve reform alternatives considered in their summary all but three are rated as keeping costs low for at least some of the policyholders. By contrast, only four of the proposals considered are rated as clearly aligning prices with risks. Three other proposals are rated as having the potential to do provide some alignment.

An important question facing coastal areas that have the prospect for increasing risks of storm related damage concerns due to climate change is whether to protect these locations with policies such those identified in the Louisiana Master Plan (Coastal Protection and Restoration 
Authority of Louisiana [2017]) or to retreat from them. That is, to adopt policies encouraging households to move away from the harm. One of the best ways to inform these decisions is to follow Stigler’s [1987] advice from his classic text on price theory and allow the prices of insurance contracts associated with these hazards to reflect the state of the information about how these risks are changing ${ }^{17}$. At present, policymakers argue we need to focus on affordability in designing insurance rates so that households in high risk areas can purchase insurance and that the program should make up the implicit subsidies by charging more to those in lower risk locations. There is an implicit assumption about the ability to pay of households in the two locations. Presumably it is expected to be lower where there are higher risks and higher in the lower risk locations. We have provided evidence that that this premise should be questioned. Our findings for the Gulf coast imply that in many locations we are subsidizing higher income households and not the ones envisioned by equity concerns.

Concerns about the affordability of insurance programs have led to subsidies in other areas. However, we argue that the design of the subsidies in the NFIP is relatively unique for two reasons. First, the potential for spatially differentiated rates provides an opportunity to provide market signals of flooding risks to new entrants. That is, actuarial based prices would indicate how risks differ by location. Second, and equally important, when subsidies are attached to specific homes and land parcels, based on historical conditions, these assets' values capitalize the implied rents. These increased values, in turn, create incentives for household to encourage local officials to modify risk maps in ways that mask flooding risks and to lobby for continuing policies that prevent insurance prices from reflecting flooding risks.

\footnotetext{
${ }^{17}$ One of the most durable messages of George Stigler's famous textbook, The Theory of Price is the role of prices as “messengers". Anyone reading Chapter two, Prices and the Enterprise Economy, easily appreciates why policies distorting market determined prices often have important unanticipated consequences. See especially pp12-16.
} 
These features contrast with other programs where insurance programs have subsidies. For example, employer subsidized rates for health insurance are not linked to assets. They can be expected to alter the wage rates these employers can offer. They are part of the compensating differentials that, in a hedonic context, affect the market equilibrium wage function ${ }^{18}$. Another prominent program justified, in part, based on affordability arguments (along with protection of family farms) is federal crop insurance. Beginning in 1996 it was transformed to a revenue insurance program associated with risks arising from crop yields and market prices ${ }^{19}$. While this program provides subsidized risk management instruments that are likely to distort incentives to farmers, the design does not lead to differential capitalization based on risks associated with differences in climate related risks to crop yields ${ }^{20}$.

Both of these programs have seen reforms in how affordability is treated in their rate designs. Our research suggests that the pending renewal of the NFIP is an opportunity to an important first step in climate adaptation policy by signaling flooding risks with spatially thru insurance prices that are based on actuarial principles.

\footnotetext{
${ }^{18}$ Of course, they can also create other incentives that influences insurance expenditures ( See Gruber and Washington[2006] ). In addition with public health insurance there is a similar problem where high risk groups cannot afford insurance. Under these circumstances it is important to ask whether prices to encourage take up of insurance and the associated subsidies to sustain the program or ex post provision of care for those who cannot afford it offers the most cost effective means of sustaining some desired level of care for all.

${ }^{19}$ See Goodwin [2005].

${ }^{20}$ It does distort land allocation between farm and non-farm uses of these lands by capitalizing the expected value of access to these programs into the farm values. It can also promote agricultural activities in areas that could not be sustained if they faced the weather risks and actuarial rates for crop insurance.
} 


\section{References}

Banzhaf, H. Spencer and Randall P. Walsh. 2008. "Do People Vote with Their Feet? An Empirical Test of Tiebout's Mechanism." American Economic Review, 98(3): 843-63.

Bin, Okmyung, John Bishop and Carolyn Kousky. 2017. “Does the National Flood Insurance Program Have Redistributional Effects?” The B.E. Journal of Economic Analysis \& Policy, 17(4):

Congressional Budget Office. 2017. The National Flood Insurance Program: Financial Soundness and Affordability (Washington, D.C.: CBO, Congress of United States, September) Coastal Protection and Restoration Authority of Louisiana. 2017. Louisiana's Comprehensive Master Plan for a Sustainable Coast, State of Louisiana.

Couvillion, BradleyR. John A. Barras, Gregory D. Steyer, William Sleavin, Michelle Fischer, Holly Beck, Nadine Trahan, Brad Griffin, and David Heckman. 2011. Land Area 
Change in Coastal Louisiana from 1932 to 2010 U.S. Geological Survey Scientific Investigations Map 3164, scale 1:265,000, 12 p. pamphlet.

The Data Center. 2017. The Coastal Index: Tracking development of the water management cluster in Southeast Louisiana, June.

Emanuel, Kerry. 2005. “Increasing Destructiveness of Tropical Cyclones Over the Past Thirty Years” Nature, 436(4):686-688.

Epple, Dennis and Holger Sieg. 1999. "Estimating Equilibrium Models of Local Jurisdiction." Journal of Political Economy, 107(4): 645-81.

Goodwin, Barry K. 2005. "Agricultural Policy Analysis: The Good, the Bad, and the Ugly.” American Journal of Agricultural Economics,97 (2): 353-373.

Gruber, Jonathan and Ebonya Washington. 2005. "Subsides to Employee Health Insurance Premiums and the Health Insurance Market.” Journal of Health Economics, 24 (2): 253-276.

Klein, Roger W. 2017. “Flood Insurance is broken. Here are some ways to fix it” The Conversation, September 19.

Knutson, Thomas and Robert E. Tuleya.2004. "Impact of $\mathrm{CO}_{2}$ Induced Warming on Simulated Hurricane Intensity and Precipitation: Sensitivity of Climate Model and Convective Parameterization” Journal of Climate, 17 (18): 3477-3495.

Kousky, Carolyn. 2017. “Disasters as Learning Experiences or Disasters as Policy Opportunities? Examining Flood Insurance Purchases After Hurricanes” Risk Analysis 37 (3):517-530. 
Kousky, Carolyn and Brett Lingle.2017. “Are Floods Getting Worse for the National Flood Insurance Program?” Resources for the Future Blog post October 11.

Kousky, Carolyn and Erwann O. Michel-Kerjan .2015. "Examining Flood Insurance Claims in the United States: Six Key Findings” Journal of Risk and Insurance 82 (1):1-32.

Kousky, Carolyn and Howard Kunreuther. 2017. "The National Flood Insurance Program: Yesterday, Today and Tomorrow” in Center for Insurance Policy and Research, Flood Risk and Insurance, April, pp. 23-45.

Michel-Kerjan, Erwann, Sabine Lemoyne de Forges, and Howard Kunreuther. 2012. “Policy Tenure under the US National Flood Insurance Program” Risk Analysis 32 (4): 644-658.

National Research Council. 2015. Committee on the Affordability of National Flood Insurance Program Premiums, Affordability of National Flood Insurance Program Premiums, Report 1 (Washington, D.C. : National Academy of Sciences)

National Research Council. 2016. Committee on the Affordability of National Flood Insurance Program Premiums, Affordability of National Flood Insurance Program Premiums, Report 2 (Washington, D.C.: National Academy of Sciences)

Natural Resources Defense Council. 2017. Seeking Higher Ground: How to break the Cycle of Repeated Flooding with Climate Smart Flood Insurance Reforms. Issue Brief 17-07-A, July.

North Carolina Floodplain Mapping Program. 2015. “National Flood Insurance Program Premiums in North Carolina: Case Study on Data Availability, Modeling, and Analysis Supporting Premium and Affordability Discussions”, July10. 
Nechyba, Thomas, J. 1997. "Existence of Equilibrium and Stratification in Local and Hierarchical Tiebout Economies with Property Taxes and Voting." Economic Theory, 10(2): 277-304.

. Sarmiento, Carmilo and Ted R. Miller. 2006. Costs and Consequences of Flooding and the Impact of the National Flood Insurance Program, Calverton, MD: Pacific Institute for Research and Evaluation, October.

Stigler, George J. 1987. The Theory of Price, Fourth edition (New York: Macmillan Publishing Co.)

Tiebout, Charles M. 1956. "A Pure Theory of Local Expenditures." Journal of Political Economy, 64(5): 416-24. 


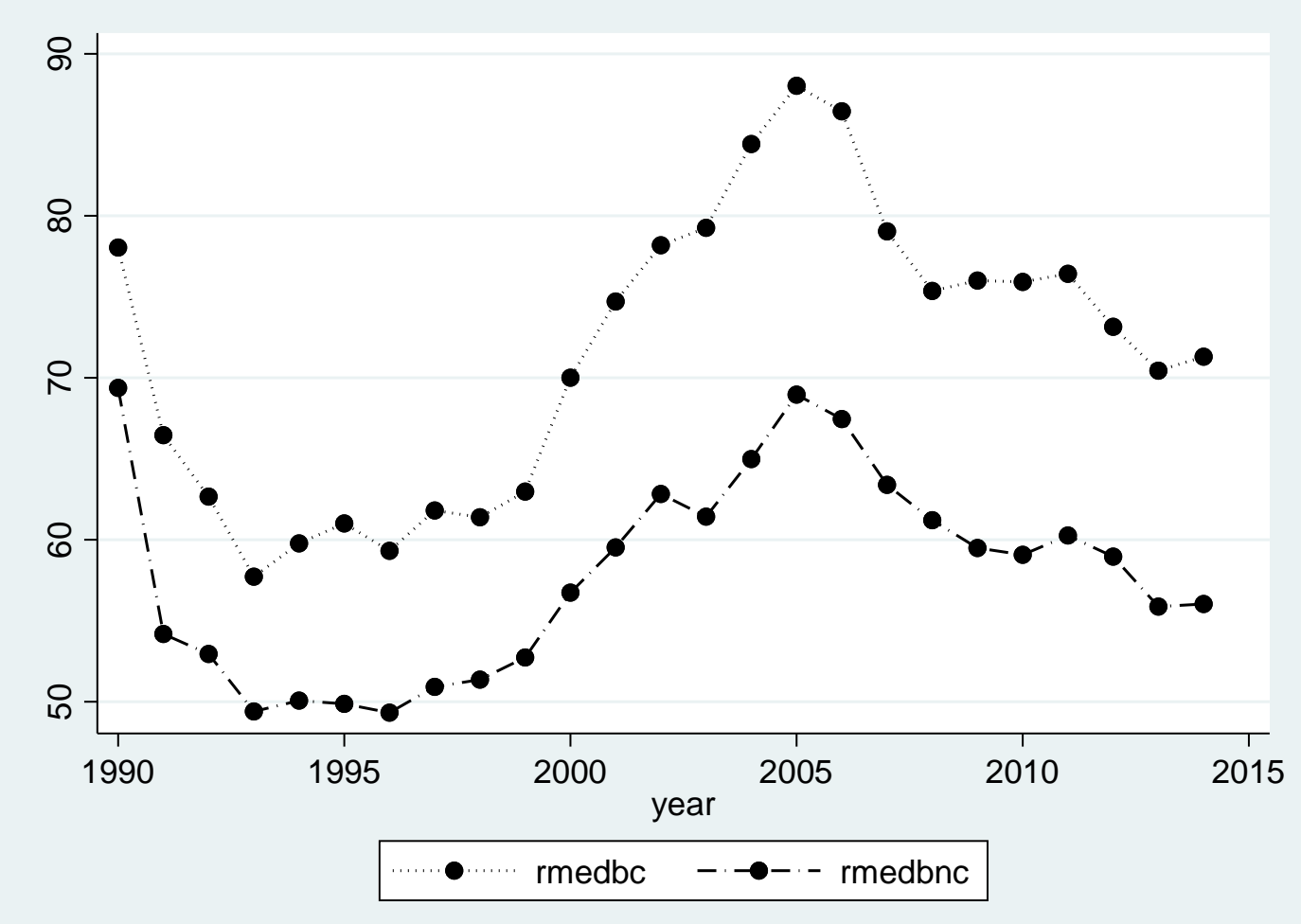

Figure 1a: HMDA Estimates for Real (\$2015) Median Income In Florida -County Model

rmedbc $=$ real median income for shoreline counties

rmedbnc $=$ real median income for interior counties 


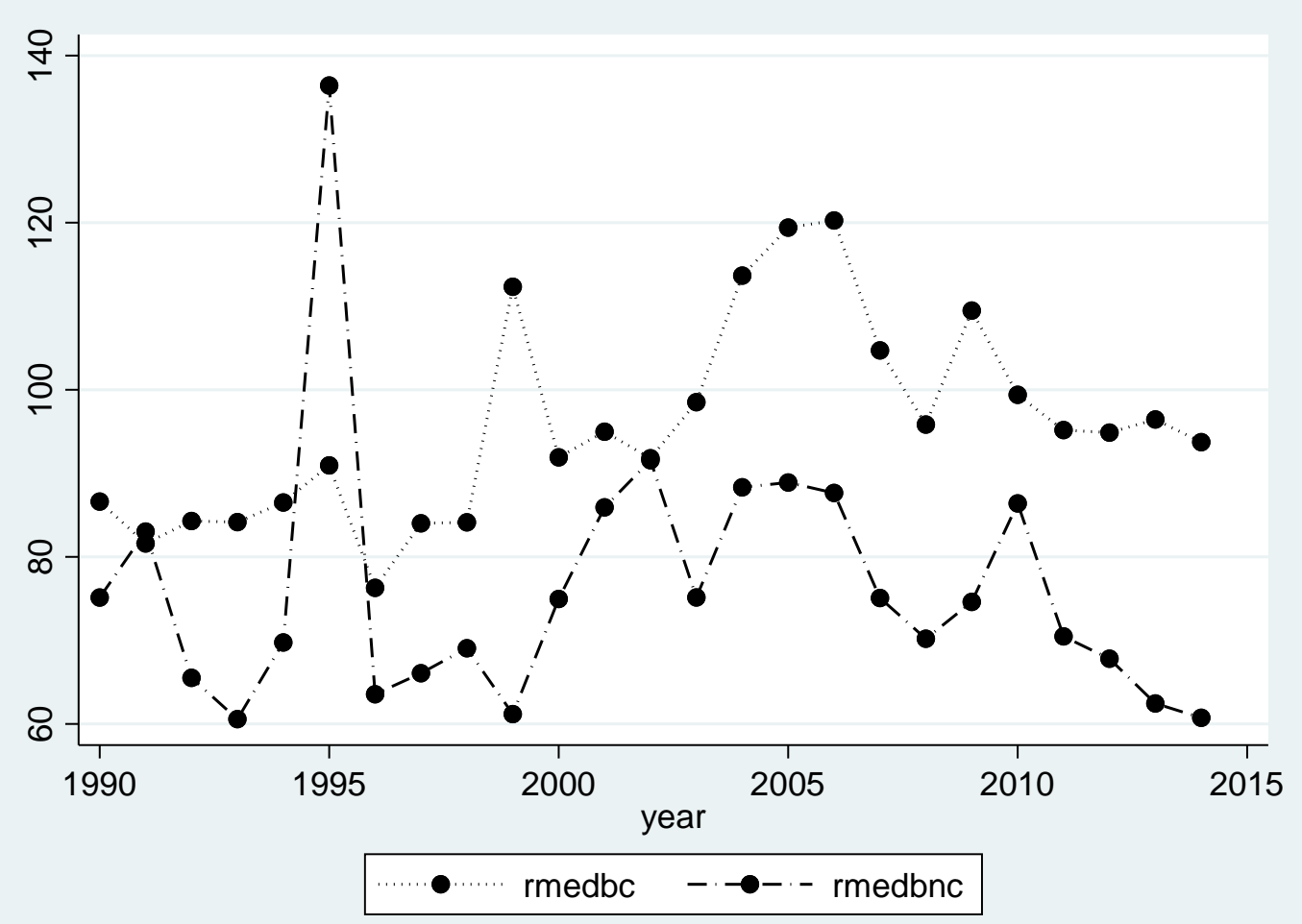

Figure 1b. HMDA Estimates for Real (\$2015) Median Income in Florida -Zip code Model

rmedbc $=$ real median income for shoreline zip codes

rmedbnc $=$ real median income for interior adjacent zip codes 


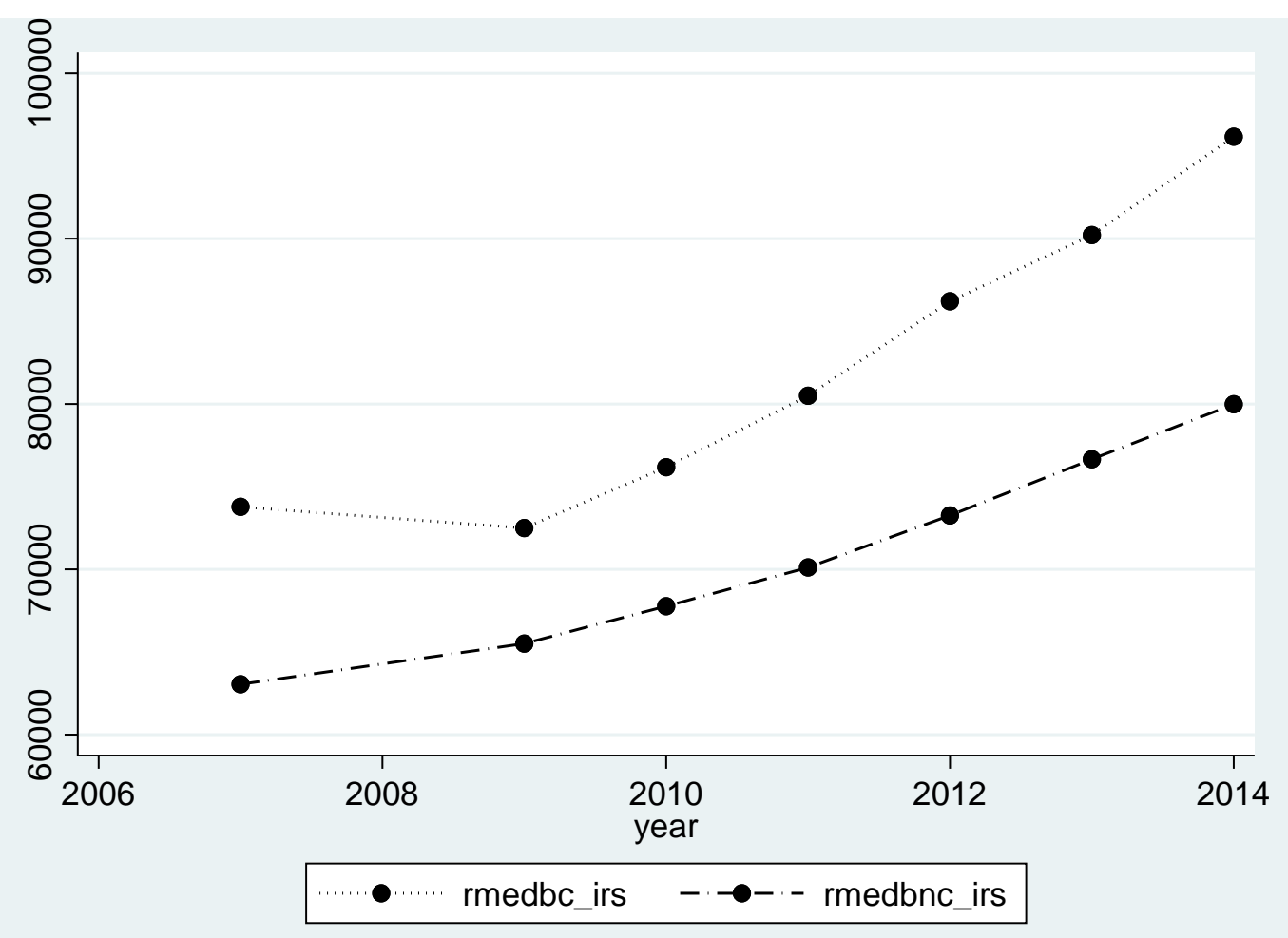

Figure 1c. IRS Estimates for Real (\$2015) Median Income in Florida -Zip code Model

Rmedbc_irs= real median income for shoreline zip codes

Rmedbnc_irs = real median income for interior adjacent zip codes 


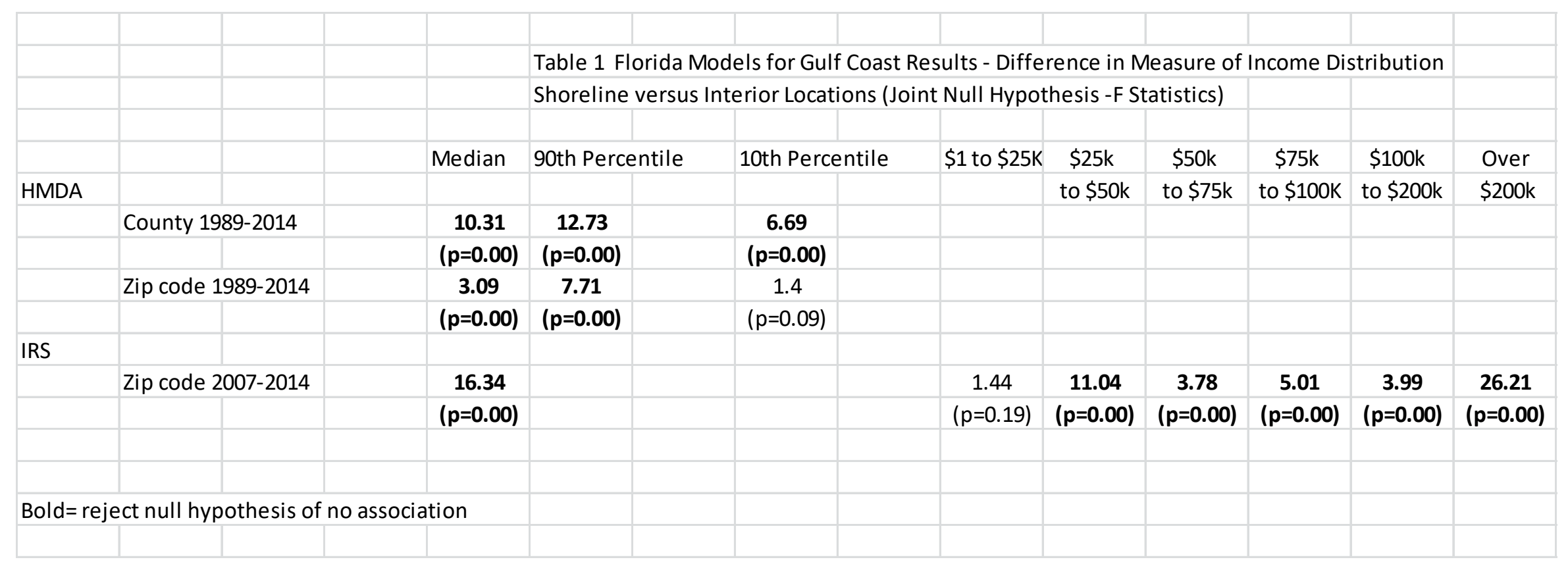




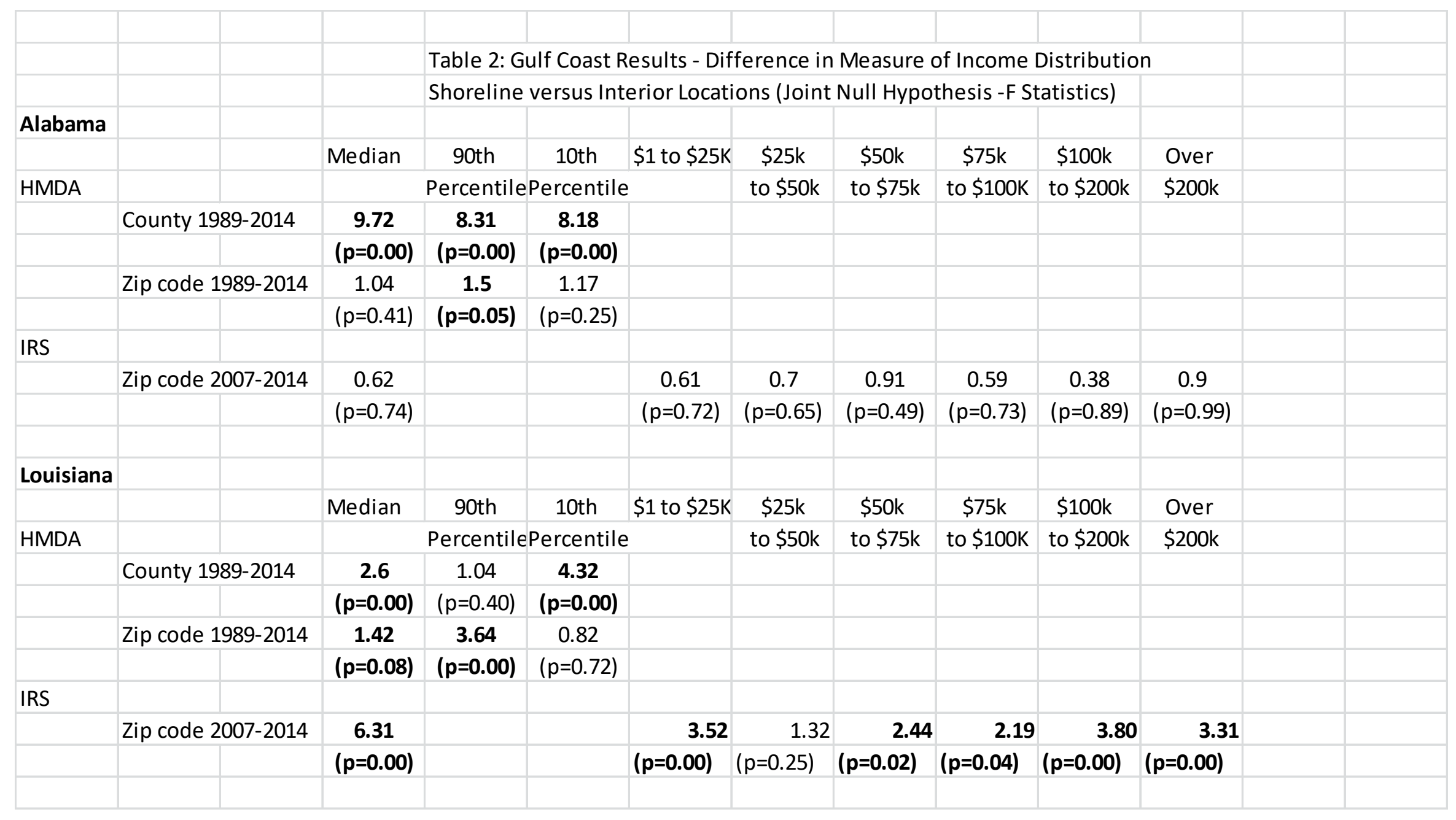




\begin{tabular}{|c|c|c|c|c|c|c|c|c|c|c|}
\hline \multirow{2}{*}{\multicolumn{2}{|c|}{ Mississippi }} & \multirow[b]{2}{*}{ Median } & \multirow[b]{2}{*}{ 90th } & \multirow[b]{2}{*}{ 10th } & \multirow[b]{2}{*}{$\$ 1$ to $\$ 25 K$} & \multirow[b]{2}{*}{$\$ 25 k$} & \multirow[b]{2}{*}{$\$ 50 k$} & \multirow[b]{2}{*}{$\$ 75 k$} & \multirow[b]{2}{*}{ \$100k } & \multirow[b]{2}{*}{ Over } \\
\hline & & & & & & & & & & \\
\hline \multirow[t]{5}{*}{ HMDA } & & \multicolumn{4}{|c|}{ PercentilePercentile } & to $\$ 50 \mathrm{k}$ & to $\$ 75 \mathrm{k}$ & to $\$ 100 \mathrm{~K}$ & to $\$ 200 \mathrm{k}$ & $\$ 200 k$ \\
\hline & County 1989-2014 & 2.73 & 1.07 & 3.45 & & & & & & \\
\hline & & $(p=0.00)$ & $(p=0.38)$ & $(p=0.00)$ & & & & & & \\
\hline & Zip code 1989-2014 & 0.95 & 1.38 & 3.49 & & & & & & \\
\hline & & $(p=0.54)$ & $(p=0.10)$ & $(p=0.00)$ & & & & & & \\
\hline \multirow[t]{3}{*}{ IRS } & & & & & & & & & & \\
\hline & Zip code $2007-2014$ & 0.80 & & & 0.75 & 0.15 & 0.69 & 1.08 & 0.67 & 1.71 \\
\hline & & $(p=0.58)$ & & & $(p=0.61)$ & $(p=0.99)$ & $(p=0.65)$ & $(p=0.38)$ & $(p=0.68)$ & $(p=0.12)$ \\
\hline & & & & & & & & & & \\
\hline & & & & & & & & & & \\
\hline \multicolumn{11}{|l|}{ Texas } \\
\hline & & Median & 90th & 10th & $\$ 1$ to $\$ 25 K$ & $\$ 25 k$ & $\$ 50 k$ & $\$ 75 k$ & $\$ 100 k$ & Over \\
\hline \multirow[t]{5}{*}{ HMDA } & & \multicolumn{4}{|c|}{ PercentilePercentile } & to $\$ 50 \mathrm{k}$ & to $\$ 75 \mathrm{k}$ & to $\$ 100 \mathrm{~K}$ & to $\$ 200 \mathrm{k}$ & \$200k \\
\hline & County 1989-2014 & 1.34 & 0.39 & 1.96 & & & & & & \\
\hline & & $(p=0.12)$ & $(p=1.00)$ & $(p=0.00)$ & & & & & & \\
\hline & Zip code 1989-2014 & 3.75 & 5.24 & 1.21 & & & & & & \\
\hline & & $(p=0.00)$ & $(p=0.00)$ & $(p=0.21)$ & & & & & & \\
\hline \multirow[t]{3}{*}{ IRS } & & & & & & & & & & \\
\hline & Zip code $2007-2014$ & 0.24 & & & 1.7 & 0.91 & 0.98 & 0.27 & 0.96 & 1.16 \\
\hline & & $(p=0.98)$ & & & $(p=0.12)$ & $(p=0.48)$ & $(p=0.44)$ & $(p=0.95)$ & $(p=0.45)$ & $(p=0.33)$ \\
\hline & & & & & & & & & & \\
\hline & & & & & & & & & & \\
\hline
\end{tabular}

